\title{
Composição da despesa com pessoal e déficit fiscal: uma análise dos Estados e do Distrito Federal
}

\section{Ronaldo Ribeiro de Oliveira}

Tribunal de Contas do Estado de Mato Grosso, Cuiabá, MT - Brasil

\section{Luiz Ricardo Cavalcante}

Consultoria Legislativa do Senado Federal, Brasília, DF - Brasil

O objetivo deste trabalho é descrever e sistematizar as diferentes interpretações do conceito de despesa com pessoal nas medidas de déficit fiscal nos Estados e no Distrito Federal. Com esse propósito, examinam-se os dados relativos à despesa total com pessoal (DTP) das 27 unidades da Federação. Os resultados indicam que em 23 delas há divergências entre os dados publicados e o entendimento da Secretaria do Tesouro Nacional (STN), as quais estão relacionadas à exclusão do Imposto de Renda Retido na Fonte (IRRF), do abono de permanência, dos pensionistas, dos inativos e da contribuição previdenciária patronal. Argumenta-se que o subdimensionamento da DTP tende a i) ampliar a margem de expansão de gastos remuneratórios; ii) criar a ilusão de enquadramento nos limites fixados pela Lei de Responsabilidade Fiscal (LRF); iii) limitar as possibilidades de sanções previstas na LRF; e iv) gerar impacto previdenciário em razão da paridade e do aumento de inativos.

Palavras-chave: despesa com pessoal, Lei de Responsabilidade Fiscal, limite fiscal 


\section{Composición de gastos de personal y déficit fiscal: un análisis de los estados y del Distrito Federal de Brasil}

El objetivo de esta investigación es describir y sistematizar las diferentes interpretaciones del concepto de gastos de personal en las medidas de déficit fiscal en los estados y en el Distrito Federal. Para este propósito, se analizan los datos sobre el gasto total de personal de las 27 unidades de la Federación. Los resultados indican que en 23 de ellas hay divergencias entre los datos publicados y las directrices de la Secretaría del Tesoro Nacional de Brasil. Las diferencias están relacionadas con la exclusión del impuesto sobre la renta retenido en la fuente, con el subsidio de permanencia en servicio, los pensionados, los inactivos y con la contribución de seguridad social del empleador. Se argumenta que las estimativas de gastos de personal bajo sus costos efectivos tienden a: i) ampliar el margen de expansión de los gastos de remuneración; ii) crear la falsa impresión de enmarcar dentro de los límites establecidos por la Ley de Responsabilidad Fiscal (LRF); iii) limitar las posibilidades de sanciones previstas en la LRF; y iv) generar impacto en la seguridad social debido a la paridad y al aumento de los inactivos.

Palabras clave: gastos de personal, Ley de Responsabilidad Fiscal, límites fiscales

\section{Composition of personnel expenses and fiscal deficit: an analysis of the Brazilian states and of the Federal District}

The aim of this paper is to describe and to systematize the changing understandings about personnel expenses in the estimations of the fiscal deficits of the states and of the Federal District in Brazil. Data regarding the total personnel expenses of the 26 states and of the Federal District were analyzed. It is shown that in 23 out of 27 units there are differences between the published data and the understanding of the National Treasury Secretariat. Differences are related to the exclusion of withholding income taxes, staying allowances, pensioners, inactive personnel and employer's contribution to social security. It is argued that underestimating personnel expenses may lead to undesirable events such as i) unsustainable expansion of remuneration expenses; ii) illusion of fiscal stability; iii) limited possibilities of applying legal sanctions to managers that are not fiscally responsible; iv) and social security impacts due to parity and increasing number of inactive workers.

Keywords: personnel expenses, Fiscal Responsibility Law, boundaries of fiscal stability 


\section{Introdução}

O desempenho fiscal impacta diretamente nos investimentos, na economia, na prestação dos serviços públicos e na qualidade de vida dos cidadãos. Por essa razão, o equilíbrio das contas públicas tem sido uma recorrente preocupação nacional. Contudo, ao longo dos últimos anos, déficits reiterados têm sido observados, ensejando a adoção de medidas de austeridade e de cortes de gastos e atrasos de repasses por parte da União aos demais entes da federação. Com efeito, segundo estudo realizado por Tinoco e Giambiagi (2018), a deterioração fiscal esteve no centro das principais discussões macroeconômicas nos últimos anos, sendo apontada como uma das causas mais importantes da recessão iniciada em 2015 e o principal pilar da reforma fiscal com imposição do teto de gastos.

Nessa seara, as despesas com pessoal são uma rubrica especialmente relevante. Com efeito, Gadelha (2011) mostra que essas despesas exercem um forte impacto na probabilidade dos municípios incorrerem em déficit. Trata-se, de acordo com o referido autor, de um item que afeta mais o resultado primário dos municípios do que as receitas tributárias.

Nos Estados e no Distrito Federal, o controle das despesas com pessoal é executado por meio de Relatórios de Gestão Fiscal (RGF), que são divulgados ao final de cada quadrimestre com o comparativo dos limites fiscais impostos pela Lei Complementar no 101, de 4 de maio de 2000 ("Lei de Responsabilidade Fiscal" ou "LRF"). Esses relatórios destacam a despesa total com pessoal (com distinção dos inativos e pensionistas) e indicam eventuais medidas corretivas adotadas ou a adotar se ultrapassados os limites fixados em lei. Medeiros et al. (2017) explicam que esses limites foram impostos devido ao histórico de desequilíbrio e endividamento dos entes subnacionais, especialmente com relação ao gasto com pessoal. Trata-se de uma rubrica que requer um controle cuidadoso, uma vez que os serviços públicos tendem a ser intensivos em mão de obra e que há diversos incentivos para que se criem despesas adicionais dessa natureza. Além disso, o aumento dos gastos com pessoal tende a aumentar os gastos previdenciários futuros. 
O conceito de despesa total com pessoal (DTP) está previsto no artigo 18 da LRF:

[...] entende-se como despesa total com pessoal: o somatório dos gastos do ente da Federação com os ativos, os inativos e os pensionistas, relativos a mandatos eletivos, cargos, funções ou empregos, civis, militares e de membros de Poder, com quaisquer espécies remuneratórias, tais como vencimentos e vantagens, fixas e variáveis, subsídios, proventos da aposentadoria, reformas e pensões, inclusive adicionais, gratificações, horas extras e vantagens pessoais de qualquer natureza, bem como encargos sociais e contribuições recolhidas pelo ente às entidades de previdência (LEI DE RESPONSABILIDADE FISCAL, art. 18).

Tal fato poderia sugerir a convergência de entendimentos acerca de quais despesas possuem essa natureza e, por conseguinte, compõem os cálculos da DTP. No entanto, na prática, há divergências capitaneadas por instituições diversas, como as Controladorias Gerais dos Estados e os Tribunais de Contas, e resultantes da interferência do Poder Judiciário. Nesses casos, o subdimensionamento da DTP tende a i) ampliar a margem de expansão de gastos remuneratórios; ii) criar a falsa impressão de enquadramento nos limites fixados pela Lei de Responsabilidade Fiscal (LRF); iii) limitar as possibilidades de sanções previstas na LRF; e iv) gerar impacto previdenciário em razão da paridade e do aumento de inativos. Contudo, apesar dessas consequências, não há registro de levantamento sistemático do reflexo das diversas compreensões acerca da concepção de despesa com pessoal nas medidas de déficit fiscal das 27 unidades da Federação.

Nesse contexto, o objetivo deste trabalho é descrever e sistematizar as diferentes interpretações do conceito de despesa com pessoal nas medidas de déficit fiscal nos estados e no Distrito Federal. Com esse propósito, analisam-se os RGF e os Relatórios Resumidos da Execução Orçamentária (RREO) disponibilizados pelos estados e Distrito Federal. O trabalho está estruturado em quatro seções além desta introdução. A seção 2 contém uma breve revisão bibliográfica sobre o tema. Na seção 3, demonstram-se os procedimentos metodológicos utilizados. Já na seção 4, apresenta-se o quantitativo de entes que excluem determinadas rubricas e suas respectivas fundamentações. Finalmente, na quinta seção discutem-se as conclusões e implicações da análise empreendida. 


\section{Fundamentos teóricos}

Apesar da relevância do tema para o debate sobre o equilíbrio fiscal, as despesas com pessoal das unidades da federação e seus métodos de apuração têm sido objeto de uma produção acadêmica relativamente escassa. Com efeito, conforme se evidencia ao longo desta seção, foram identificados poucos trabalhos publicados em periódicos sobre o tema, embora haja uma razoável produção técnica na forma, por exemplo, de manuais ou textos para discussão.

Campagnoni et al. (2014) analisaram os limites para despesas com pessoal, estabelecidos na LRF, pelos Poderes e órgãos da União no período de 2000 a 2013. O trabalho avalia, inclusive, se os limites apurados respeitaram as determinações da LRF, mas não trata de jurisdições subnacionais. Outros estudos avaliam a composição e a evolução das despesas com pessoal em Estados como Santa Catarina e Mato Grosso do Sul, mas não se detêm nos métodos empregados na apuração dessas despesas (SouzA; Platt Neto, 2012; Pires; Platt Neto, 2016).

Em meados da década de 2000, ao analisar o ajuste fiscal promovido no período de 1999 a 2003, Dias (2004, p. 32) alertou para a resistência dos entes subnacionais às regras da LRF e para a necessidade de racionalização na gestão fiscal. Alguns anos mais tarde, esse mesmo autor (DIAS, 2009, p. 31) salientou que os estados têm se valido de interpretações ou contestações da LRF para se adequarem aos limites para a despesa com pessoal. Oliveira (2015, p. 266-270), ao analisar a LRF, alerta para a melhora artificial da relação "despesa com pessoal /receita corrente líquida", em decorrência da exclusão indevida do IRRF. Afonso e Pinto (2016), por sua vez, mencionam as "leituras heterodoxas do que contar ou não como despesa de pessoal".

De acordo com Rocha (2018, p. 11), somente a partir da publicação da 1a edição do Boletim de Finanças dos entes subnacionais, em 2016, tornou-se possível comparar as despesas com pessoal apuradas pela Secretaria do Tesouro Nacional (STN) - órgão pertencente ao Ministério da Economia que possui a competência de estabelecer normas e procedimentos atinentes à execução orçamentária e financeira aos entes federativos com aquelas informadas pelos governos estaduais por meio dos RGF. O Boletim de Finanças 
dos Entes Subnacionais 2018 da STN (BRASIL, 2018), com base nos dados do Programa de Reestruturação e Ajuste Fiscal (PAF), constatou que, em 2017, 14 estados apresentaram comprometimento de suas receitas correntes líquidas com despesas com pessoal superior ao limite de 60\% fixado na $L R F(A C, A L, B A, M G, M S, M T, P B, P R, R J, R N, R R, R S, S C$ e SE). No entanto, segundo as informações publicadas pelos entes nos RGF relativos a 2017, apenas seis estados encontrar-se-iam acima do limite de 60\% da LRF (AC, MG, MS, RJ, RR e TO). Essa diferença, como se destacou no boletim, é proveniente das diversas metodologias (sancionadas pelos respectivos Tribunais de Contas) dos cálculos da despesa com pessoal.

O caso do Estado de Mato Grosso é exemplificativo de distorção dos dados contábeis, amparada em decisão do respectivo Tribunal de Contas, que impacta diretamente nas informações fiscais do estado. Em dezembro de 2015, o governo do estado, de forma consolidada, apresentava 60,40\% de gastos com despesa de pessoal, nos termos do RGF, acima, portanto, do limite máximo previsto na LRF, que é de $60 \%$. Com uma decisão do Tribunal de Contas do Estado de Mato Grosso (TCE-MT), por meio da Resolução de Consulta 29, de dezembro de 2016, mudou-se o entendimento até então vigente e passou-se a adotar uma linha interpretativa divergente da STN, no sentido de não se incluir na apuração da despesa com pessoal e na receita corrente líquida $(R C L)$ o valor do IRRF dos servidores. Com essa decisão, o referido limite de despesa com pessoal caiu para 56,98\%, já em dezembro de 2016, nos termos do RGF, deixando de demonstrar, dessa forma, a verdadeira situação fiscal do estado e possibilitand o o incremento de novas despesas com pessoal. Posteriormente, em dezembro de 2018, mediante a Resolução de Consulta n 19/18, o TCE-MT alterou novamente seu entendimento técnico acerca da consideração do IRRF no conceito de despesa com pessoal, retornando à antiga linha argumentativa de que o IRRF deve sim compor a despesa com pessoal e a RCL, culminando, dessa forma, na elevação da despesa com pessoal para $68,18 \%$, conforme RGF do terceiro quadrimestre de 2018, o que, atualmente, traz enormes dificuldades de adequação ao limite máximo de $60 \%$, considerando a rigidez das despesas com pessoal e dificuldade de se aumentarem receitas.

A Federação das Indústrias do Estado do Rio de Janeiro (FIRJAN, 2019) emitiu Nota Técnica em abril de 2019, alertando para o aumento das despesas com pessoal, as divergências de metodologias de cálculo e a ausência de transparência e de possibilidade de comparação da real situação dos entes. 
Nota-se, assim, que os trabalhos que existem acerca do assunto mencionam que há divergências de metodologias e cálculos da despesa com pessoal, as quais refletem na grave situação fiscal contemporânea dos entes, porém não aprofundam e não demonstram, de forma sistemática (isto é, para o conjunto das unidades da Federação e para o conjunto das possíveis exclusões) quais são essas divergências.

\section{Procedimentos metodológicos}

A fim de alcançar o objetivo apontado na introdução deste trabalho, a bibliografia sobre o tema foi revisada, encontrando-se pouco conhecimento sistematizado sobre o assunto. Na sequência, estudaram-se casos práticos, jurisprudência e experiências relacionadas ao tema.

Em seguida, coletaram-se os RGF publicados pelos estados e Distrito Federal dos últimos dez anos, tendo como marco final o RGF do 3ㅇ quadrimestre de 2018, com exame dos dados relativos à despesa total com pessoal (DPT), especialmente no que diz respeito à exclusão de valores com fundamento em entendimentos técnicos e decisões judiciais que, em regra, são mencionados nas notas de rodapé dos RGF, as quais serão analisadas e catalogadas.

Dando continuidade ao trabalho, realizou-se levantamento das informações de déficit fiscal dos estados e do Distrito Federal com base nos anexos um e quatro dos Relatórios Resumidos da Execução Orçamentária dos últimos dez anos, respectivamente.

Com base nesses dados, demonstram-se os impactos das alterações metodológicas e interpretativas no cálculo da despesa com pessoal, considerando a metodologia de cálculo adotada pelo ente e a forma definida pela STN.

Como a pesquisa que resultou neste artigo tem um caráter fundamentalmente documental, optou-se por registrar, nas referências, apenas livros, artigos publicados em periódicos ou trabalhos de caráter acadêmico. No caso da legislação citada, dos RGF, das decisões, das resoluções ou dos pareceres coletivos, entre outros documentos legais ou infralegais que formam, na prática, a base empírica deste trabalho, optou-se por indicar a numeração correspondente para que possam ser diretamente obtidos na internet em sites jurídicos, legislativos ou nos próprios portais de transparência dos entes federativos. 


\section{Resultados: sistemáticas adotadas pelos entes da federação na apuração da despesa com pessoal}

A LRF tem seu fundamento nos artigos 163 e 169 da Constituição Federal, os quais estabelecem que cabe a lei complementar dispor sobre finanças públicas e limites de despesa com pessoal. A LRF consolidou-se como ferramenta basilar de planejamento e controle das receitas e despesas públicas, estabelecendo regras referentes à responsabilidade e ao equilíbrio da gestão fiscal.

Como mecanismo de contenção e tentativa de controle de tais gastos, a LRF, em seu artigo 18, fixou os elementos que devem compor a despesa total com pessoal (DPT), considerando, para tanto, quaisquer gastos remuneratórios com ativos, inativos e pensionistas. Já o artigo $19, \S 10$, prevê quais rubricas devem ser excluídas do cálculo de despesa com pessoal, tais como indenização por demissão de servidores ou empregados, incentivos à demissão voluntária decorrentes de decisão judicial, dentre outras. O cômputo da despesa líquida com pessoal se dá entre a diferença da despesa bruta com pessoal (somatório das despesas com pessoal ativo, inativo, pensionistas e outras despesas com pessoal) e as despesas não computadas.

A LRF prevê, assim, os limites de gastos com despesa com pessoal em harmonia com a capacidade de arrecadação de tributos, com a finalidade de controlar as finanças públicas dos entes federativos. Logo, os Estados e o Distrito Federal possuem o limite global de gastos com pessoal de $60 \%$ de sua receita corrente líquida, subdividido em limites específicos de 3\% ao Poder Legislativo (incluídos os Tribunais de Contas), 6\% ao Judiciário, 49\% ao Executivo e 2\% ao Ministério Público. Caso ultrapassem os limites impostos pela LRF, cabe ao Poder ou órgão reenquadrar seus gastos nos dois semestres subsequentes, eliminando o percentual excedente. Caso a redução não seja efetivada, o ente não poderá receber transferências voluntárias, obter garantia de outro ente ou contratar operações de crédito.

Os mecanismos de controle previstos nos $\S \S 1$ e e 20 do artigo 23 da LRF estão suspensos liminarmente desde 2007 (ADI no 2.238), pois o Supremo Tribunal Federal (STF) entendeu que a parte final do $\S 10$, o qual prevê redução da remuneração dos cargos em comissão e funções de confiança, não possui previsão na Constituição Federal. Pela mesma 
razão, o § 2ํ foi suspenso, uma vez que possibilitaria a redução temporária de jornada de trabalho com a adequação de vencimentos. Isto é, o STF decidiu pelo afastamento da eficácia de parte do §1ㅇ e da integralidade do §2으 do artigo 23 da LRF, por considerar que as normas contidas nesses dispositivos atentam contra o princípio da irredutibilidade de vencimentos. De acordo com a Suprema Corte, as medidas de redução da remuneração de cargos e de funções e a redução de vencimentos compensada pela redução de carga horária de serviço não encontram respaldo na Carta Magna, que cuida da contenção de despesas públicas com pessoal. O julgamento do mérito somente foi iniciado em 2019, mas o STF ainda não o concluiu. Assim, o estado que ultrapassou ou venha a ultrapassar o limite máximo de despesa com pessoal não é obrigado e nem pode lançar mão das alternativas de redução previstas nos $§ \S 1$ ㅇ e 2 ㅇ do artigo 23 da LRF.

A receita corrente líquida $(\mathrm{RCL})$ corresponde às diversas receitas arrecadadas pelo estado no mês de referência e nos onze anteriores e demonstra os recursos que o governo possui em cada exercício para fazer frente às suas despesas. Consoante o artigo 2으, IV, da LRF, a RCL compõe-se do somatório de receitas tributárias, contribuições, patrimoniais, industriais, agropecuárias, de serviços, transferências correntes e outras receitas correntes. Desse valor, subtraem-se, no caso dos estados, as parcelas entregues aos municípios por determinação constitucional e outras deduções.

Como forma de adequação aos limites previstos em lei, os Estados e o Distrito Federal deveriam buscar alternativas para não aumentar gastos e reduzir despesas remuneratórias, a exemplo da não realização de novos concursos públicos e a não concessão de aumento salarial para categorias profissionais.

Todavia, por vezes, os entes baseiam-se em metodologias fundamentadas em decisões provenientes dos Órgãos de Controle e das Cortes Superiores e Estaduais, as quais têm fixado entendimentos que afetam diretamente o cálculo da despesa com pessoal, ora não contabilizando as rubricas expressamente previstas no artigo 18, ora deixando de computar despesas que, embora não mencionadas no rol do mencionado dispositivo, notadamente possuem natureza remuneratória, o que acarreta implicações econômicas e financeiras. Nesse sentido, alguns estados não consideram em suas despesas com pessoal algumas rubricas de despesas importantes, como as despesas com inativos e pensionistas, Imposto de Renda Retido na Fonte e as despesas com obrigações patronais. 
Assim, tais decisões têm gerado interpretações distintas entre os entes federados e a STN, o que é perceptível ao analisar os RGF dos Poderes. Isso se deve ao fato de que, ao se excluir verba de natureza remuneratória da despesa com pessoal, inevitavelmente, a margem do limite do ente aumenta. Isso provoca uma falsa ideia de que há espaço para a realização de novas despesas, considerando a diminuição do percentual de gasto com pessoal, ou seja, embora o ente efetivamente tenha extrapolado o limite considerado seguro para o gasto com pessoal, o RGF sugere que ele ainda comportaria novas despesas.

Além dessa maquiagem impedir a imposição de medidas da LRF para a retomada do limite, a existência de espaço para comportar novas despesas coloca o ente em situação de vulnerabilidade frente às pressões das categorias profissionais por concessões de revisão geral anual, aumentos, benefícios e realização de concursos públicos, por exemplo.

Desse modo, a fim de traçar um diagnóstico da situação fiscal dos estados, analisaram-se as metodologias adotadas no cômputo das espécies remuneratórias. De acordo com o levantamento realizado, mais de $70 \%$ das deliberações relacionadas à despesa com pessoal são lastreadas em decisões dos Tribunais de Contas dos Estados. Para corroborar o versado, nas próximas seções serão demonstrados quais Poderes e órgãos dos estados excluem as referidas rubricas e as fundamentações que justificariam sua não inclusão na despesa com pessoal.

\subsection{Imposto de Renda Retido na Fonte}

O IRRF é uma das formas de arrecadação do Imposto de Renda (IR) cuja competência arrecadatória é da União. No entanto, as receitas derivadas do IRRF pertencem exclusivamente aos Estados, ao Distrito Federal e aos Municípios, por determinação constitucional.

Contudo, o assunto causa interessantes debates quanto à inclusão da rubrica em estudo na composição da RCL e da DPT, sendo necessário compreender primeiramente que, ao realizar o pagamento da remuneração, o IRRF é retido pelo ente, ou seja, na fonte. Questiona-se, então, se esse valor retido deve ser contabilizado na RCL e na DPT. Alguns Poderes e órgãos, ao reter o IRRF, entendem que não. Em relação à RCL, acreditam que a retenção do referido imposto não configura receita, mas mero registro contábil, já que não 
há pagamento direto pelo contribuinte aos cofres públicos. Quanto à DPT, compreendem que a parcela retida da remuneração dos servidores a título de IRRF não pode ser configurada como despesa porque não houve saída de valores dos cofres públicos.

Todavia, a exclusão do IRRF, tanto na RCL, como na DPT, viola o princípio do orçamento bruto, previsto na Lei no 4.320/1964, o qual determina que as receitas e despesas devem constar no orçamento pelos seus valores globais, sem quaisquer deduções. Ademais, a retenção do IRRF é receita efetiva e ocasiona aumento quantitativo do patrimônio do ente beneficiado. Há que se pontuar também que a STN já se posicionou no sentido de que o IRRF deve ser incluído no cálculo das despesas com pessoal por ter caráter remuneratório. Porém, considerando os RGF do 3ำ quadrimestre de 2018, verificou-se que em 15 estados, pelo menos em um Poder ou em um órgão, ocorre a exclusão da arrecadação do IRRF do cálculo de despesa com pessoal.

\section{Quadro 1 | Exclusão do IRRF}

\begin{tabular}{|c|c|c|c|c|c|c|}
\hline & Executivo & $\begin{array}{c}\text { Tribunal de } \\
\text { Justiça }\end{array}$ & $\begin{array}{l}\text { Assembleia } \\
\text { Legislativa }\end{array}$ & $\begin{array}{c}\text { Tribunal de } \\
\text { Contas }\end{array}$ & $\begin{array}{c}\text { Ministério } \\
\text { Público }\end{array}$ & Consolidado \\
\hline $\mathrm{AP}$ & & & & $x$ & $x$ & \\
\hline $\mathrm{BA}$ & & $x$ & & & & \\
\hline $\mathrm{GO}$ & $x$ & $x$ & $x$ & & $x$ & $x$ \\
\hline MA & & $x$ & $x$ & $x$ & $x$ & \\
\hline MS & & $x$ & & & $x$ & \\
\hline $\mathrm{MT}\left({ }^{*}\right)$ & $x$ & & $x$ & $x$ & $x$ & $x$ \\
\hline PA & & & $x$ & $x$ & & \\
\hline PB & $x$ & & & $x$ & $x$ & $x$ \\
\hline RO & & $x$ & $x$ & & $x$ & \\
\hline $\mathrm{RR}$ & & & $x$ & $x$ & & \\
\hline $\mathrm{RS}$ & $x$ & & & & $x$ & $x$ \\
\hline $\mathrm{RN}$ & & $x$ & & $x$ & $x$ & \\
\hline SC & & & & & $x$ & \\
\hline SE & & & $x$ & $x$ & $x$ & \\
\hline TO & & & $x$ & $x$ & & \\
\hline
\end{tabular}

(*) No Estado de Mato Grosso, até o 2ㅇ quadrimestre de 2018, visualiza-se a exclusão do IRRF na Assembleia Legislativa, Poder Executivo e Consolidado no cômputo de despesa com pessoal para fins de limite, conforme preconiza a LRF. No Ministério Público Estadual, a exclusão da referida rubrica foi constatada apenas até o 1ํ quadrimestre de 2018. Fonte: elaboração própria. 
O Tribunal de Contas do Estado do Rio Grande do Norte (TCE-RN), por exemplo, entende que o IRRF referente aos servidores públicos não integra os conceitos de "despesa com pessoal" e de "receita corrente líquida", para fins de apuração dos limites estabelecidos na LRF, sob o fundamento de que "os valores referentes ao IRRF dos servidores públicos não aumentam nem reduzem os valores dos cofres estaduais, sendo uma operação meramente escritural" (TCE-RN, Decisão no 720/207). Desse entendimento compartilha o Tribunal de Contas do Estado do Rio Grande do Sul (TCE-RS), pois julga também que só se considera receita quando há entrada efetiva de recurso e, por conseguinte, variação patrimonial. Nesse viés, não considera o IRRF como receita porque não há efetiva incorporação de recursos ao patrimônio público (TCE-RS, Parecer Coletivo no 2/2002).

Ancorado sobre os mesmos argumentos, em 2016 o TCE-MT posicionou-se também a favor da exclusão do IRRF da RCL e da DPT, por meio da Resolução de Consulta no 29/2016. Entretanto, em 2018, mediante reexame de tese, tal entendimento foi revisto por considerar que destoava da legislação e jurisprudência. Deste modo, o TCE-MT decidiu que o IRRF não pode ser excluído do cômputo das DPT e deve ser incluído no cálculo da RCL (TCE-MT, Resolução de Consulta no 19/2018).

\subsection{Abono de permanência}

O abono de permanência é um incentivo pecuniário conferido ao servidor público que, atendendo aos pressupostos para aposentadoria voluntária, possui a faculdade em permanecer na ativa, fazendo jus ao recebimento de valor equivalente à sua contribuição previdenciária - a qual é de responsabilidade do ente público em que o servidor é vinculado -, enquanto não satisfaz os requisitos para aposentadoria compulsória, conforme previsto no artigo 40 da Carta Magna.

Possui, assim, duas vertentes: é um estímulo ao servidor a permanecer na ativa, já que recebe numerário igual ao de sua contribuição, e é uma economia para a administração pública, visto que não necessita contratar imediatamente novo servidor para repor aquele que iria se aposentar, protelando as despesas que teria com proventos de aposentadoria e mantendo em atividade servidor capacitado. Consoante Ibrahim (2008), a concessão do abono permanência é importante para o adequado funcionamento da máquina administrativa, adiando a saída de pessoas especializadas em seus segmentos de atividade. 
É preciso levar em consideração que o servidor continua contribuindo para o regime próprio a que se encontra vinculado, mas recebe em valor idêntico o abono de permanência, na mesma folha de pagamento, gerando, por fim, vantagem financeira em sua remuneração, em razão de sua permanência na ativa. Assim, não há prejuízos aos cofres previdenciários, sendo de total responsabilidade do Tesouro o pagamento do abono no mesmo valor da contribuição.

Destaque-se que o abono de permanência possui natureza transitória, devendo ser concedido ao servidor somente até o momento de sua aposentadoria eletiva ou compulsória aos 75 anos de idade, conforme preceitua a Emenda Constitucional 88/2015.

Outrossim, é importante discutir a natureza jurídica do abono de permanência, posto que sua interpretação está intimamente ligada ao cálculo da despesa com pessoal do ente federativo e, a depender da perspectiva adotada, fomenta, incontestavelmente, grande impacto no equilíbrio financeiro do ente, em razão dos limites previstos nos artigos 18,19 e 20 da LRF.

É certo que o Constituinte não foi claro se a verba em comento é de ordem remuneratória ou indenizatória, o que provoca interessantes debates jurídicos nas Cortes Superiores e nos Órgãos de Controle, considerando que a LRF, ao dispor da composição da DPT com pessoal, elencou os gastos de natureza remuneratória com ativos, inativos e pensionistas, não se fazendo, contudo, menção a qualquer tipo de espécie indenizatória.

Embora parte considerável da jurisprudência enverede para a natureza indenizatória do abono de permanência, é assente na maioria das cortes de controle e judiciais que a vantagem em comento possui essência remuneratória e, portanto, integra a despesa com pessoal, por se tratar de uma retribuição pelos serviços prestados em razão do esforço laboral em permanecer na ativa, não se tratando de prejuízos a serem indenizados, tampouco de gastos a serem ressarcidos; ademais, compreendem que o abono de permanência compõe o patrimônio jurídico do servidor, o que desconfigura sua natureza indenizatória.

Do mesmo modo, o Superior Tribunal de Justiça (STJ), em análise acerca da essência do abono de permanência, decidiu que a verba em estudo ostenta natureza remuneratória sob o argumento de que se trata de vantagem permanente, uma vez que o auxílio somente 
cessa quando o servidor se aposenta (STJ, Recurso Especial: 1489929 RS 2014/02714798). O Tribunal de Contas da União (TCU) também entende que o abono de permanência tem reconhecido caráter remuneratório e não indenizatório (TCU, Acórdão no 1209/2011 - Plenário). A Receita Federal do Brasil (RFB), ao estabelecer normas gerais de tributação relativas ao Imposto de Renda das Pessoas Físicas, nutriu o argumento de que o abono de permanência reside de natureza remuneratória, porquanto, conforme artigo 22 , $\S$ 3으, da Instrução Normativa RFB n. 1500/2004, o incentivo deve ser considerado como rendimento de trabalho e, desse modo, sujeito à incidência de IRRF (RFB).

O Manual de Demonstrativos Fiscais da STN, aplicável à União, aos Estados, ao Distrito Federal e aos Municípios, também perfilha do entendimento de que o abono de permanência, enquanto elemento da despesa bruta com pessoal, possui natureza remuneratória. Desse modo, deve ser computado no cálculo de despesa com pessoal. Embora o Manual disponha, assim como a LRF, que as despesas com inativos e pensionistas, custeadas com recursos vinculados, não são consideradas no cálculo da despesa para fins de limite, é necessário relembrar que o servidor que recebe abono de permanência está em atividade, não fazendo parte dos inativos, ainda que preencha todos os requisitos para a inatividade.

Em outro giro, há juristas que entendem que o abono de permanência possui natureza indenizatória. Primeiro, porque a Lei no 10.887/2004, que trata do cálculo dos proventos de aposentadoria, em seu artigo 4으, § 1으, exclui o abono de permanência da base de cálculo para a contribuição social do servidor público, o que, para muitos, desconfigura sua natureza remuneratória. Segundo, porque o servidor, quando decide permanecer na ativa, renuncia a um direito e, por isso, recebe a verba em estudo como compensação pelo tempo a maior conferido à administração pública. E é nessa oportunidade, conforme aduz Elias (2009), que o abono de permanência revela sua natureza indenizatória, ao compensar pecuniariamente o servidor pela postergação do exercício de um direito que possui, qual seja, o de se aposentar.

Especificamente no tocante à atuação dos Órgãos de Controle, o Tribunal de Contas do Estado do Ceará (TCE-CE) e o Tribunal de Contas do Estado de Santa Catarina (TCE-SC) entendem que as verbas pagas a título de abono de permanência não devem ser incluídas no cômputo da despesa com pessoal para fins de limite de gastos da LRF, por possuir 
natureza indenizatória e compensatória, uma vez que o servidor, ao não requerer seu direito de aposentadoria no momento que perfaz o preenchimento de todos os requisitos, recebe o abono a título de indenização (TCE-CE, Resolução no 2582/2009; TCE-SC, Decisão no 893/2017). O TCE-MT também perfilha o mesmo entendimento das demais cortes citadas, por entender que o abono de permanência possui caráter indenizatório, e vai além, afirma que a vantagem em estudo não compõe a base essencialmente remuneratória utilizada para o cálculo da contribuição previdenciária, não se incorpora aos proventos de aposentadoria, não é vantagem permanente e não representa acréscimo patrimonial para o servidor (TCE-MT, Resolução de Consulta no 27/2016).

Todavia, da totalidade das unidades da federação, apenas oito excluem o abono de permanência das despesas com pessoal, enquanto as demais acompanham o entendimento jurídico da STN, do TCU, da Receita Federal e do STJ, além dos próprios tribunais de contas, no sentido de conferir a tal rubrica o conceito remuneratório e, portanto, incluir nas despesas com pessoal e configurar no RGF.

Para fins de observância do limite de gastos com pessoal, os Poderes e órgãos dos oito estados abaixo não incluem o abono de permanência em seu cálculo, conforme averiguado em seus RGF do 3ㅇ quadrimestre de 2018:

\section{Quadro 2 | Exclusão do Abono de Permanência}

\begin{tabular}{|c|c|c|c|c|c|c|}
\hline & Executivo & $\begin{array}{c}\text { Tribunal de } \\
\text { Justiça }\end{array}$ & $\begin{array}{c}\text { Assembleia } \\
\text { Legislativa }\end{array}$ & $\begin{array}{c}\text { Tribunal de } \\
\text { Contas }\end{array}$ & $\begin{array}{c}\text { Ministério } \\
\text { Público }\end{array}$ & Consolidado \\
\hline $\mathrm{BA}$ & $x$ & $x$ & & $x$ & $x$ & $x$ \\
\hline CE & $x$ & $x$ & $x$ & $x$ & $x$ & \\
\hline MT & $x$ & & $x$ & $x$ & $x$ & $x$ \\
\hline PE & $x$ & $x$ & $\mathrm{x}$ & $x$ & $x$ & $x$ \\
\hline $\mathrm{PI}$ & & $x$ & & & & \\
\hline RS & $x$ & & & & $x$ & $x$ \\
\hline SC & & $x$ & $x$ & $x$ & $x$ & \\
\hline TO & & & $x$ & & & \\
\hline
\end{tabular}

Fonte: elaboração própria. 


\subsection{Pensionistas}

Com o advento da LRF, surge também uma das discussões acadêmicas mais acirradas acerca da composição das equações de gastos com pessoal, porquanto em seu artigo 18 trouxe a previsão de que a despesa com pessoal seria composta pelo gasto de ativos, inativos e pensionistas. O cerne da discussão jurídico-doutrinária cingese à inclusão ou não dos pensionistas no cômputo de gastos com pessoal, sendo parte da doutrina contrária a tal inclusão, vertendo pela inconstitucionalidade por abuso do poder normativo complementar do artigo 18 da LRF, uma vez que a Constituição Federal somente atribuiu competência à lei complementar para estabelecer limites de gastos com pessoal ativo e inativo, e que não seria o caso de inclusão de pensionistas que, juridicamente, são distintos dos inativos. Diferentemente da LRF, a Constituição Federal não previu expressamente a inclusão desses dispêndios com pensionistas na despesa com pessoal, limitando-se a mencionar literalmente tão somente gastos com ativos e inativos, nos termos de seu artigo 169.

Além das interpretações jurídico-doutrinárias, tal discussão aportou às Cortes de Contas do país. O Tribunal de Contas do Distrito Federal (TCDF) e o TCE-CE entenderam pela exclusão dos gastos com pensionistas do cálculo de despesas com pessoal para fins de verificação do cumprimento da LRF, face à inexistência textual de previsão Constitucional nesse sentido (TCDF, Decisão no 1.905/2013; TCE-CE, Resolução no 2.230/2010).

O Estado de Goiás promoveu, recentemente, a alteração de sua Constituição, por meio da Emenda no 55/2017, em que estabeleceu, com modulação de efeitos, em seu artigo 113, que "não serão computadas as despesas com pensionistas para fins de verificação do atendimento pelo estado dos limites globais" previstos na LRF, desde o período de apuração do RGF do 2o quadrimestre de 2017.

De outro lado, Rocha (2018) explana que a Lei Maior em vários momentos usa a expressão "inativo" como gênero, contemplando as espécies "aposentados" e "pensionistas", e que, sendo a LRF a responsável por definir as normas gerais de finanças públicas, cabe a ela especificar a composição da despesa com pessoal. 
Quando da análise dos RGF dos Poderes e órgãos, do 3ㅇquadrimestre de 2018, constata-se que em quatro estados da Federação não há a inclusão dos pensionistas no cálculo da despesa com pessoal, sendo eles:

Quadro 3 | Exclusão dos pensionistas

\begin{tabular}{|c|c|c|c|c|c|c|}
\hline & Executivo & $\begin{array}{l}\text { Tribunal de } \\
\text { Justiça }\end{array}$ & $\begin{array}{l}\text { Assembleia } \\
\text { Legislativa }\end{array}$ & $\begin{array}{c}\text { Tribunal de } \\
\text { Contas }\end{array}$ & $\begin{array}{c}\text { Ministério } \\
\text { Público }\end{array}$ & Consolidado \\
\hline CE & $x$ & & $x$ & $x$ & $x$ & \\
\hline $\mathrm{DF}$ & & $x$ & $x^{(*)}$ & $x$ & & \\
\hline $\mathrm{GO}$ & $x$ & $x$ & $x$ & & $x$ & $x$ \\
\hline $\mathrm{RS}$ & $x$ & & & & $x$ & $x$ \\
\hline $\mathrm{SP}$ & & & & $x$ & & \\
\hline PR & & & & & $x$ & \\
\hline
\end{tabular}

$\left(^{*}\right)$ Câmara Legislativa.

Fonte: elaboração própria.

\subsection{Inativos e pensionistas}

Outra interpretação que causa divergência no cômputo da despesa com pessoal refere-se à não inclusão dos inativos e pensionistas nos limites específicos de cada Poder e órgão, previstos no artigo 20 da LRF.

De acordo com as orientações do Manual de Demonstrativos Fiscais da STN (BRASIL, 2019), as despesas com inativos e pensionistas compõem a DPT e, por isso, devem ser computadas nos RGF de cada Poder ou órgão:

Todos os poderes e órgãos disciplinados no art. 20 da LRF devem apresentar, no seu demonstrativo, a parcela das despesas com inativos vinculados a esse poder ou órgão. Para permitir a elaboração do Demonstrativo da Despesa com Pessoal com essas informações, o RPPS deverá manter registros destacados das receitas e despesas de cada um dos Poderes. O RPPS deve, ainda, ter condições de fornecer as informações necessárias que possibilitem ao respectivo Poder ou órgão utilizar tais informações para fins de elaboração do seu RGF, mediante apuração dos valores brutos de inativos e pensionistas, assim como do montante de inativos e pensionistas pagos com recursos do RPPS (BRASIL, 2019; grifos dos autores). 
Segundo o Manual, o que pode ser deduzido (não computado) no cálculo da DPT são apenas despesas com inativos e pensionistas custeadas com recursos vinculados, ou seja, provenientes da arrecadação de contribuições dos segurados e receitas diretamente arrecadadas por fundo destinado a tal finalidade. Assim, tais despesas que não forem custeadas com os referidos recursos não poderão ser deduzidas do cálculo da DPT. Nesse sentido, Furtado (2013) argumenta que:

[...] os dispêndios com inativos e pensionistas devem ser incluídos no cômputo da despesa total com pessoal, para efeito de verificação do cumprimento dos limites impostos pela Lei Complementar no 101/ (LRF), salvo quando custeadas por recursos previdenciários próprios, tal como definido no art. 19, §1으, IV. (FURTADO, 2013)

Em que pesem essas orientações, alguns Poderes e órgãos adotam posicionamento contrário ao da STN, incluindo a despesa com inativos e pensionistas apenas no cômputo do limite global do ente da federação, ignorando sua inclusão nos limites específicos previstos no artigo 20 da LRF.

A compreensão do Tribunal de Contas do Estado do Maranhão (TCE-MA) ilustra bem o referido contexto. Essa Corte de Contas inclui os gastos com inativos e pensionistas no cálculo da despesa com pessoal, porém não os contabiliza no momento da apuração de seu limite individual previsto no artigo 20 da LRF (TCE-MA, Decisão no 1895/2002). O Tribunal de Contas do Estado da Paraíba (TCE-PB) também entende que as despesas com inativos não podem ser consignadas especificamente nos Poderes e Órgãos, sob o fundamento de que o gerenciamento das receitas e despesas previdenciárias somente é possível ao Poder Executivo. Assim, em sede de consulta, o TCE-PB respondeu, com amparo no parecer do Ministério Público de Contas, da seguinte forma:

Os gastos com inativos não integram a despesa total de pessoal para fins de verificação do cumprimento dos limites específicos de cada Poder e órgão; previstos no artigo 20, da LRF, compondo-a apenas para efeito de confrontação com o limite global de cada Ente da Federação (TCE-PB, Parecer no 77/2007).

Nessa mesma vertente, verifica-se que o Ministério Público do Estado do Rio Grande do Norte também não contabiliza os gastos com inativos e pensionistas em seu RGF (TCERN, Acórdão 265/2018). 
O que se pode perceber, ao analisar os RGF do 3o quadrimestre de 2018 , é que um número vultoso de Poderes e órgãos realiza o cômputo da despesa com inativos e pensionistas de forma divergente da propagada pela STN, conforme Quadro 4 abaixo:

Quadro 4 | Exclusão dos inativos e pensionistas

\begin{tabular}{|c|c|c|c|c|c|c|}
\hline & Executivo & $\begin{array}{c}\text { Tribunal de } \\
\text { Justiça }\end{array}$ & $\begin{array}{c}\text { Assembleia } \\
\text { Legislativa }\end{array}$ & $\begin{array}{c}\text { Tribunal de } \\
\text { Contas }\end{array}$ & $\begin{array}{l}\text { Ministério } \\
\text { Público }\end{array}$ & Consolidado \\
\hline MA & & $x$ & $x$ & $x$ & $x$ & \\
\hline MG & & & $x$ & & & \\
\hline MT & & & & $x$ & & \\
\hline MS & $x$ & & & $x$ & & \\
\hline PB & $x$ & $x$ & & $x$ & $x$ & \\
\hline RJ & & $x$ & & $x$ & $x$ & \\
\hline $\mathrm{RN}$ & & & & & $x$ & \\
\hline RO & & $x$ & $x$ & $x$ & $x$ & \\
\hline SE & & & $x$ & $x$ & $x$ & \\
\hline TO & & $x$ & $x$ & $x$ & $x$ & \\
\hline
\end{tabular}

Fonte: elaboração própria.

\subsection{Contribuição patronal}

Consoante artigo 40 da Constituição Federal, aos servidores titulares de cargos efetivos é assegurado o regime de previdência de caráter contributivo e solidário, mediante contribuição dos servidores ativos, inativos e pensionistas, e do respectivo ente público (contribuição patronal). Desse modo, a Lei no 9.717/1998 - que dispõe sobre as regras gerais para a organização e funcionamento dos RPPS - estabelece que a contribuição patronal, de responsabilidade do órgão ao qual servidor estiver vinculado, não poderá ser inferior ao valor da contribuição do servidor ativo, nem superior ao dobro desta contribuição. Do mesmo modo, o artigo 18 da LRF preceitua a inclusão das contribuições patronais no cálculo da despesa com pessoal. 
Entretanto, não é unânime nas interpretações jurisprudenciais que a contribuição patronal compõe a despesa com pessoal. Evidentemente, a inclusão ou não dessa rubrica repercute intensamente quando o assunto se refere à composição das despesas com pessoal, vez que modifica substancialmente os patamares previstos na LRF.

Vale lembrar que a DPT é composta pelos gastos remuneratórios com ativos, inativos e pensionistas, além dos encargos sociais e das contribuições recolhidas pelo ente às entidades de previdência, sendo deduzidas de seu cômputo as despesas com inativos e pensionistas custeadas com recursos vinculados, até o limite da receita do RPPS, a qual é composta pela arrecadação das contribuições previdenciárias, da compensação financeira entre regimes, dentre outras.

A STN, em seu Manual de Demonstrativos Fiscais (BRASIL, 2019), dispõe que o conceito de despesa bruta com pessoal inclui também despesas de natureza previdenciária, inclusive as contribuições recolhidas pelo ente às entidades de previdência. Especifica, ainda, que a contribuição patronal ao RPPS deve ser registrada por Poder ou órgão, no item "obrigações patronais". O teor jurisprudencial emanado pelo TCU, cuja pertinência é indiscutível para o tema ora tratado, aponta na mesma direção, qual seja, de que as contribuições patronais compõem o rol de despesas do artigo 18 (TCU, Processo TC-017.522/2005-1). Em caso mais recente, o TCE-RN decidiu, em sede de consulta, que a contribuição dos servidores possui natureza de receita tributária e, desse modo, não pode ser considerada despesa com pessoal (TCE-RN, Processo no 12.704/2013). Entretanto, no que se refere à contribuição patronal, considerou que o mesmo raciocínio não se aplica, motivo pelo qual a contribuição do ente inclui-se no cálculo de despesa com pessoal.

Há, porém, entendimento jurisprudencial divergente, originado do TCE-PB, que ao ser consultado pelo Ministério Público do Estado e pela Assembleia Legislativa acerca da inclusão da contribuição patronal na composição da despesa com pessoal, respondeu que a contribuição do ente não integra a despesa com pessoal de Poderes e órgãos, para os fins do artigo 20 da Lei Complementar no 101/2000. O relator justifica em sua decisão que o artigo 18 da LRF, ao definir despesa com pessoal, inclui - além dos dispêndios com inativos e pensionistas - as contribuições recolhidas pelo ente às entidades de previdência. No entanto, o relator dispõe em seu voto que, na verificação 
do atendimento dos limites previstos no artigo $19, \S 1$ 으, VI, da LRF, não serão computadas as despesas com inativos. Desse modo, entende que não haveria lógica deduzir os gastos com inativos sem a consequente exclusão da parcela dos encargos decorrentes da obrigação patronal. Já o TCE-MT, em que pese não haver justificativa nas notas de rodapé de seu RGF, exclui a contribuição patronal da sua composição com despesa com pessoal. Sua justificativa não trata de inconstitucionalidade ou ilegalidade, mas sim de ausência de dotação orçamentária suficiente para fazer frente ao pagamento de contribuição patronal sobre inativos.

Como resultado, no 3o quadrimestre de 2018, o TCE-MT e o Ministério Público da Paraíba excluem a contribuição patronal do cálculo da despesa com pessoal:

\section{Quadro 5 | Exclusão da Contribuição Patronal}

\begin{tabular}{|c|c|c|c|c|c|c|}
\hline & Executivo & $\begin{array}{c}\text { Tribunal de } \\
\text { Justiça }\end{array}$ & $\begin{array}{c}\text { Assembleia } \\
\text { Legislativa }\end{array}$ & $\begin{array}{c}\text { Tribunal de } \\
\text { Contas }\end{array}$ & $\begin{array}{c}\text { Ministério } \\
\text { Público }\end{array}$ & Consolidado \\
\hline MT & & & $x$ & \\
\hline PB & & & & & $x$ \\
\hline
\end{tabular}

Fonte: elaboração própria.

\subsection{Consolidação dos Resultados}

Com base na análise dos RGF do 3o quadrimestre de 2018 (com exceção do Estado de Mato Grosso, para o qual os RGF são do 10 e 2 ㅇq quadrimestre) e nas informações constantes em notas de rodapé, pode-se identificar as exclusões de rubricas relacionadas às despesas com pessoal nos estados e no Distrito Federal. Essas rubricas envolvem o IRRF, o abono de permanência, os pensionistas, os inativos e pensionistas e a contribuição patronal. As exclusões estão indicadas no Quadro 6 a seguir: 
Quadro 6 | despesas excluídas e total das exclusões por unidade da Federação, 2018

\begin{tabular}{|c|c|c|c|c|c|c|}
\hline Unidade da Federação & IRRF & $\begin{array}{c}\text { Abono de } \\
\text { Perma- } \\
\text { nência }\end{array}$ & $\begin{array}{l}\text { Pensio- } \\
\text { nistas }\end{array}$ & $\begin{array}{l}\text { Inativos } \\
\text { e pensio- } \\
\text { nistas }\end{array}$ & $\begin{array}{l}\text { Contri- } \\
\text { buição } \\
\text { patronal }\end{array}$ & Total \\
\hline Acre & & & & & & 0 \\
\hline Amapá & $x$ & & & & & 1 \\
\hline Amazonas & & & & & & 0 \\
\hline Alagoas & & & & & & 0 \\
\hline Bahia & $x$ & $x$ & & & & 2 \\
\hline Ceará & & $x$ & $x$ & & & 2 \\
\hline Distrito Federal & & & $x$ & $x$ & & 2 \\
\hline Espírito Santo & & & & & & 0 \\
\hline Goiás & $x$ & & $x$ & & & 2 \\
\hline Maranhão & $\mathrm{x}$ & & & $x$ & & 2 \\
\hline Mato Grosso & $\mathrm{x}$ & $x$ & & $x$ & $x$ & 4 \\
\hline Mato Grosso do Sul & $x$ & & & $x$ & & 2 \\
\hline Minas Gerais & & & & $x$ & & 1 \\
\hline Pará & $x$ & & & & & 1 \\
\hline Paraná & & & $x$ & & & 1 \\
\hline Paraíba & $\mathrm{x}$ & & & $x$ & $x$ & 3 \\
\hline Piauí & & $x$ & & & & 1 \\
\hline Pernambuco & & $x$ & & & & 1 \\
\hline Rio de Janeiro & & & & $x$ & & 1 \\
\hline Rio Grande do Norte & $\mathrm{x}$ & & & $x$ & & 2 \\
\hline Rio Grande do Sul & $x$ & $x$ & $x$ & & & 3 \\
\hline Rondônia & $\mathrm{x}$ & & & $x$ & & 2 \\
\hline Roraima & $\mathrm{x}$ & & & & & 1 \\
\hline São Paulo & & & $x$ & & & 1 \\
\hline Santa Catarina & $x$ & $x$ & & & & 2 \\
\hline Sergipe & $\mathrm{x}$ & & & $x$ & & 2 \\
\hline Tocantins & $x$ & $x$ & & $x$ & & 3 \\
\hline Total & 15 & 8 & 6 & 11 & 2 & 42 \\
\hline
\end{tabular}

Fonte: elaboração própria. 
Com base na Tabela, constata-se que:

- Poderes e órgãos de 22 estados e do Distrito Federal excluem pelo menos uma rubrica da despesa com pessoal.

- O Estado de Mato Grosso é o que mais exclui rubricas que deveriam ser contabilizadas na despesa com pessoal.

- Paraíba, Rio Grande do Sul e Tocantins são as unidades federativas que excluem três rubricas, sendo o IRRF a despesa em comum não contabilizada por elas.

- Dez estados excluem duas despesas. Desses entes, oito não computam o IRRF e seis não contabilizam os gastos com inativos e pensionistas.

- Apenas nos estados do Acre, Alagoas, Amazonas e Espírito Santo não há divergência com o preconizado pela STN, conforme visualizado nas notas de rodapé dos RGF.

- O IRRF e os gastos com inativos e pensionistas são as rubricas excluídas com mais frequência da despesa com pessoal dos estados.

- A contribuição patronal não é contabilizada somente por duas unidades federativas (Mato Grosso e Paraíba).

O referido levantamento não tem a pretensão de exaurir, solucionar ou indicar um posicionamento acerca de qualquer sistemática adotada. O desafio que aqui se propõe, em síntese, é demonstrar o entendimento contraditório entre os próprios entes e instituições e também em relação à Secretaria do Tesouro Nacional, e refletir sobre as consequências para as finanças públicas dos Estados e do Distrito Federal. Tampouco se pretendeu estimar o impacto dessas exclusões nas despesas totais com pessoal das 27 unidades da federação. Contudo, com um propósito meramente ilustrativo, os apêndices 1 e 2 contêm essas estimativas para os Estados de Mato Grosso (onde houve o maior número de exclusões) e de Goiás. 


\section{Conclusão}

Ambicionou-se com o presente trabalho descrever e sistematizar as diferentes interpretações do conceito de despesa com pessoal nas medidas de déficit fiscal nos estados e no Distrito Federal. Com esse propósito, foram analisadas as sistemáticas relativas aos cálculos dos dados relativos à despesa total com pessoal (DTP) das 27 unidades da Federação. Inicialmente, o trabalho de identificação e sistematização se deu por meio da análise dos RGF do 3ㅇ quadrimestre dos anos de 2009 a 2018 de todos os Poderes e órgãos e do consolidado de todos os estados e DF, com exceção do Estado de Goiás, cuja verificação do consolidado de 2018 se deu por meio do Relatório de Avaliação das Metas Fiscais, em razão de não ter sido localizado o RGF.

Com isso, constatou-se que 23 unidades da Federação excluíam ou ainda excluem algum tipo de rubrica da DPT. As exclusões envolveram o abono de permanência, a contribuição patronal, os pensionistas, os inativos e o IRRF. O resultado do mapeamento mostrou, por exemplo, que o Estado de Mato Grosso é o que mais exclui rubrica da composição da despesa com pessoal (total de quatro) e o IRRF e os gastos com inativos e pensionistas são as despesas excluídas com mais frequência nas unidades federativas.

Demonstrou-se ainda que os fundamentos das decisões que amparam as exclusões provêm, em sua maior parte, dos Tribunais de Contas. Outros embasamentos decorrem de decisões judiciais, de emendas às constituições, como no Estado de Goiás, ou da própria interpretação da legislação posta. Em síntese, acerca do IRRF, argumenta-se que não deve compor a despesa com pessoal em razão de não haver dispêndio efetivo por parte da administração pública, somente operação contábil. Quanto ao abono de permanência, alguns defendem tratar-se de verba de natureza indenizatória e compensatória, e não remuneratória. No que se refere aos gastos com inativos e pensionistas, a justificativa é a de que devem compor a despesa com pessoal somente do RGF consolidado do ente da federação, e não de cada Poder e órgão individualmente. Em relação aos gastos com pensionistas, as normativas alicerçam-se no fato de a CF delegar à lei complementar competência para estabelecer limites de gastos com pessoal somente de ativos e inativos, não englobando textualmente os pensionistas. No que diz respeito à contribuição patronal, a tese é de que possui natureza de receita tributária e por isso não deve compor os gastos remuneratórios. 
O subdimensionamento da despesa com pessoal em razão da exclusão de rubricas que deveriam ser consideradas está associado a um conjunto de eventos que podem ser sintetizados da seguinte forma:

- O ente federativo passa a ter maior margem de expansão para gastos de natureza remuneratória. Nesse caso, essa margem fictícia fomenta a pressão por aumentos remuneratórios, criação ou aumento de gratificações, além de autorizar o gestor a contratar mais servidores, sendo que, em qualquer dessas situações, há um acréscimo de despesa obrigatória e continuada que pressiona, de modo invisível, o já engessado orçamento do estado, gerando crises fiscais recorrentes.

- O ente passa a se enquadrar no limite de despesa com pessoal quando na realidade já o havia ultrapassado. Nesse caso, a distorção nos números faz com que o gestor não seja obrigado a acionar os mecanismos de controle da despesa com pessoal previstos na legislação, o que, inevitavelmente, conduzirá as finanças do estado, cedo ou tarde, ao colapso.

- Além disso, essa forma criativa de contabilização da DPT livra os gestores e o ente federado das sanções cabíveis, como a reprovação das contas pelos tribunais de contas, proibição de recebimento de recursos voluntários, obtenção de certidão negativa, eventual crime de responsabilidade, dentre outras.

- Por fim, a expansão da DPT decorrente de seu subdimensionamento tende a gerar impacto previdenciário em razão da paridade e do aumento de inativos.

A análise sugere que a legislação atual acerca da definição do conceito de despesa com pessoal e do estabelecimento de mecanismos de controle é satisfatória, o que não significa que não pode ser aprimorada. Quanto ao conceito de despesa com pessoal, entende-se que a LRF foi suficientemente clara em sua definição. O problema são as várias interpretações dadas ao artigo 18. Uma possível solução para essa questão envolve o acordo de cooperação técnica celebrado em 2018 entre a Associação dos Membros dos Tribunais de Contas do Brasil (Atricon), o Instituto Rui Barbosa (IRB) e a STN, a fim de, entre outros objetivos, harmonizar conceitos e procedimentos de gestão fiscal. 
De qualquer modo, um eventual desdobramento deste trabalho pode envolver a avaliação dos montantes que, nas 23 unidades da federação indicadas, são excluídos pelos Poderes e órgãos indicados ao longo da seção 4 . Uma estimativa dessa natureza pode revelar que, em vários casos, o comprometimento das receitas correntes com despesas com pessoal já ultrapassou largamente os limites fixados em lei e requeridos para uma gestão fiscal sustentável. Com efeito, a irresponsabilidade fiscal é tão gravosa como a corrupção, haja vista que o resultado final de ambas as condutas é o mesmo na seara pública, qual seja, a ausência de recursos suficientes para o bom funcionamento de serviços tão caros ao cidadão, como a saúde, a educação, a segurança, o saneamento básico e o transporte.

\section{Referências bibliográficas}

Afonso, J. R; Pinto, V. C. Despesa Estadual com Pessoal Ativo e do Executivo: uma comparação entre unidades federadas. Caderno Virtual (Instituto Brasiliense de Direito Público), 2, 2016.

BRASIL. Ministério da Fazenda. Secretaria do Tesouro Nacional. Manual de Demonstrativos Fiscais: aplicados à União e aos Estados, Distrito Federal e Municípios. Brasília: Ministério da Fazenda, 2019.

BRASIL. Ministério da Fazenda. Secretaria do Tesouro Nacional. Boletim de Finanças Públicas dos Entes Subnacionais 2018. Brasília: Ministério da Fazenda, 2018.

Campagnoni, M; Platt Neto, O. A; CRUz, F. A observância dos limites para despesas com pessoal entre Poderes e órgãos da União no período de 2000 a 2013. Cadernos da Escola do Legislativo, v. 16, n. 26, p. 137-171, 2014.

DIAS, F. A. C. O refinanciamento dos governos subnacionais e o ajuste fiscal 1999/2003 (texto para discussão no 17). Brasília: Consultoria Legislativa do Senado Federal, 2004.

DIAS, F. A. C. O controle institucional das despesas com pessoal (texto para discussão no 54). Brasília: Consultoria Legislativa do Senado Federal, 2009.

ELIAS, G. T. Regime jurídico do abono de permanência. Revista do Tribunal de Contas do Estado de Minas Gerais, v. 72, n. 3, p. 78-89, 2009.

FEDERAÇÃo dAS INDÚSTRIAS do ESTADO DO RIO DE JANEIRO (FIRJAN). A situação fiscal dos estados brasileiros (nota técnica abril de 2019). Rio de Janeiro: Firjan, 2019. 
FurtAdo, J. R. C. Direito Financeiro. 4. ed. rev. ampl. e atual. Belo Horizonte: Fórum, 2013.

GADELhA, S. R. de B. Análise dos impactos da Lei de Responsabilidade Fiscal sobre a despesa de pessoal e a receita tributária nos municípios brasileiros: um estudo com modelo probit aplicado a dados em painel. Revista Brasileira de Gestão de Empresas, v. 11, n. 1, p. 65-77, 2011.

IBRAhIM, F. Z. Curso de Direito Previdenciário. 12. ed., Rio de Janeiro: Editora Impetus, 2008.

MedeIRos, K. R; et al. Lei de Responsabilidade Fiscal e as despesas com pessoal da saúde: uma análise da condição dos municípios brasileiros de 2004 a 2009. Ciências e saúde coletiva, v. 22, n. 6, p. 1759-1769, 2017.

OliveIRA, W. Curso de Responsabilidade Fiscal: direito, orçamento e finanças públicas. 2. ed., Belo Horizonte: Fórum, 2015.

Pires, A. L; Platt Neto, O. A. Observância dos Limites para a Despesa com Pessoal no Estado de Mato Grosso do Sul. Revista de Auditoria, Governança e Contabilidade, v. 4, n. 14, p. 37-52, 2016.

RochA, C. A. A. A despesa total com pessoal na ótica da STN e dos Tribunais de Contas Estaduais e municipais (boletim legislativo no 71). Brasília: Consultoria Legislativa do Senado Federal, 2018.

SouzA, P; Platt Neto, O. A. A composição e a evolução das despesas com pessoal no estado de Santa Catarina de 2000 a 2011. Revista Catarinense da Ciência Contábil, Florianópolis, v. 11, n. 33, p. 66-81, 2012.

TINoco, G; GIAMBIAGI, F. O crescimento da economia brasileira 2018-2023 (perspectivas Depec 2018). Rio de Janeiro: BNDES, 2018.

\section{Ronaldo Ribeiro de Oliveira}

ID ORCID: https://orcid.org/0000-0003-0428-5130

Conselheiro Substituto do Tribunal de Contas do Estado de Mato Grosso. Mestre em Administração Pública - Políticas Públicas e Gestão Governamental (IDP, 2019). Pós-graduado em Direito do Estado (FGV, 2012). Pós-graduado em MPA Executivo em Controle Externo (FGV, 2006). Pós-graduado em Gestão Pública (Faculdade Afirmativo, 2004). Pós-graduado Auditoria das Entidades Governamentais (UFMT, 2002). Master de Planejamento Público, Responsabilidade Fiscal e Execução Orçamentária (Atame, 2005).

E-mail: ronaldo@tce.mt.gov.br

\section{Luiz Ricardo Cavalcante}

(iD) ORCID: https://orcid.org/0000-0003-1894-7238

Consultor Legislativo do Senado Federal. Professor do Mestrado em Administração Pública do Instituto Brasileiro de Ensino, Desenvolvimento e Pesquisa (IDP). Mestre e doutor em Administração.

E-mail: luiz.ricardo.teixeira.cavalcante@gmail.com 


\section{Apêndice 1: O Estado de Mato Grosso}

Em dezembro de 2015 o Governo do Estado de Mato Grosso, de forma consolidada, apresentava $60,40 \%$ de gastos com despesa de pessoal, ultrapassando o limite global previsto no artigo 19 da LRF.

No ano seguinte, esse indicador recuou de maneira considerável e passou a ser de 56,98\%, após decisão do TCE/MT, a qual possibilitou a exclusão do IRRF do cálculo da despesa com pessoal e da composição da receita corrente líquida, ficando o estado dentro do limite global de $60 \%$, porém acima do limite de alerta, conforme RGF do 3 o quadrimestre de 2016. Nesse momento, se o IRRF incidente sobre a folha de pessoal fosse considerado no cômputo da despesa total com pessoal (DPT), a despesa extrapolaria o limite global em 12 milhões de reais.

Em 2017, a despesa com pessoal continuava elevada, acima do limite prudencial, mesmo não considerando o IRRF. Essa expansão decorreu da concessão de RGA em 2016 e em parte de 2017, pelo aumento do contingente de servidores ativos, proveniente de concursos, pelas progressões e promoções inerentes às carreiras (crescimento vegetativo), dentre outros fatores responsáveis pelo crescimento da despesa remuneratória de forma continuada ao longo dos anos. Naquele ano, caso o IRRF fosse considerado, a DPT seria de 254 milhões acima do permitido pela LRF, o que corresponde à metade do déficit fiscal de 2018 em Mato Grosso (R\$ 558 milhões). Assim, se o estado tivesse tomado medidas a fim de estancar o crescimento da despesa, poderia ter diminuído substancialmente seu déficit fiscal.

Todavia, em dezembro de 2018, o TCE-MT reviu seu entendimento e passou a adotar seu posicionamento anterior, o mesmo da STN, no sentindo de incluir o IRRF na apuração da despesa com pessoal e na composição da receita corrente líquida, consubstanciando em 68,18\% de despesa com pessoal em relação à RCL. O Gráfico 1 registra os percentuais da RCL aplicados na DPT entre 2015 e 2018 destacando, nos anos em que houve a exclusão do IRRF, também os percentuais considerando essa rubrica. 


\section{Gráfico 1 | Comparativos dos percentuais da RCL aplicados na despesa com pessoal do Estado de Mato Grosso (2015 - 2018)}

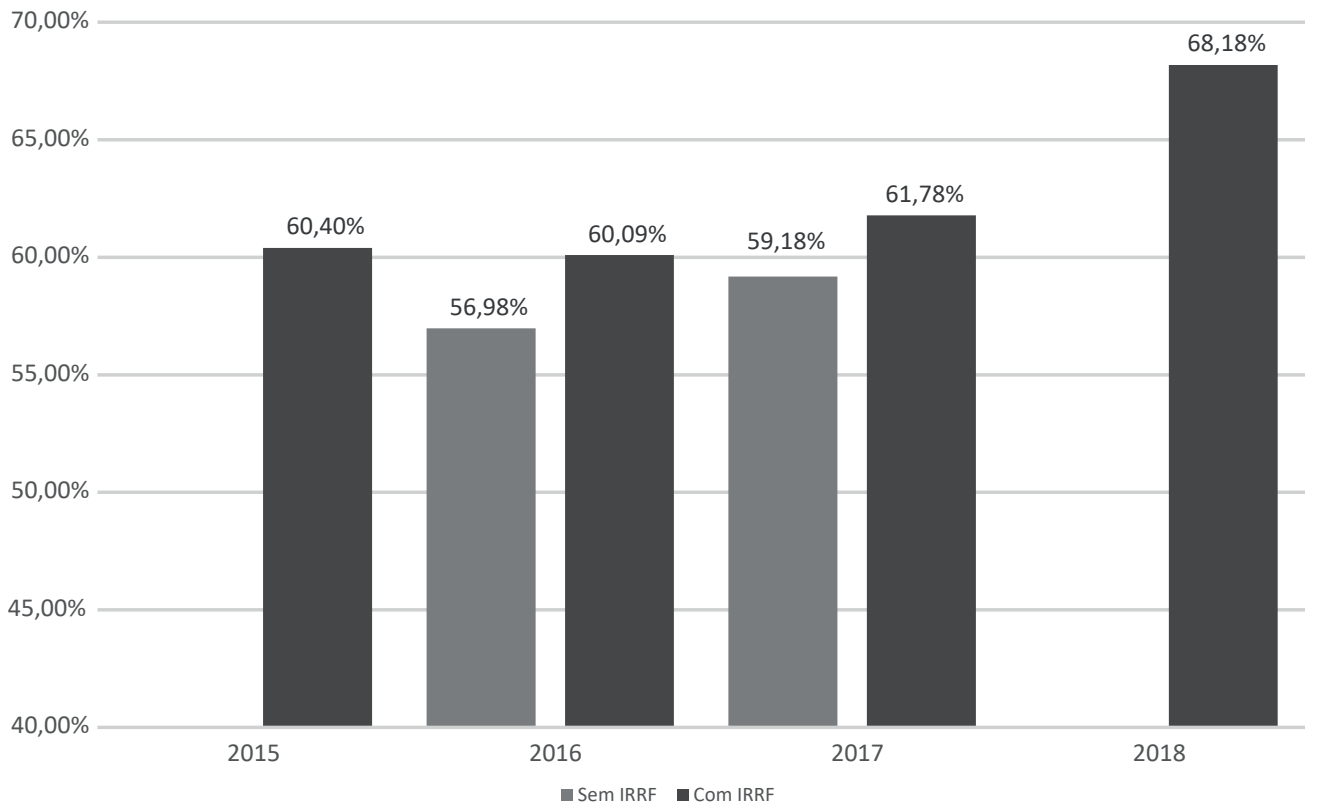

Fonte: elaboração própria.

O patamar observado em 2018 é preocupante: o estouro do limite de gastos com pessoal importou em mais de $R \$ 1,240$ bilhão de reais ao ano, cerca de $R \$ 103$ milhões de reais em despesa com pessoal acima do permitido por lei a cada mês. Esse fator justifica, em parte, a situação de calamidade financeira decretada no início de 2019 no âmbito da administração pública do Estado de Mato Grosso.

Ao observar os dados, constata-se o impacto que a alteração de metodologia do cálculo da despesa de pessoal produz. No quadrimestre anterior à alteração de entendimento exarada pela Corte de Contas do Estado (3 quadrimestre/2018), a despesa com pessoal era cerca de $10 \%$ menor, em razão da supressão do IRRF. 


\section{Apêndice 2: O Estado de Goiás}

Entre 2009 e 2018, a relação DPT/RCL do Estado de Goiás, que exclui duas rubricas da despesa com pessoal consolidada (IRRF e pensionistas), não ultrapassou o limite máximo definido pela LRF. Contudo, as projeções indicam que há déficit fiscal e previdenciário e, em janeiro de 2019, foi decretado estado de calamidade financeira.

Essa situação é mais bem compreendida quando se analisam brevemente as decisões que levaram o Estado de Goiás a não computar o IRRF e os pensionistas na despesa total com pessoal (DPT). Aqui é preciso salientar que, diferentemente de Mato Grosso, Goiás exclui o IRRF somente da despesa com pessoal, mantendo-o na composição da RCL.

Inicialmente, as Resoluções no 405/2001 e nํ 1.491/2002 do TCE-GO deram guarida às exclusões. Entretanto, em 2016, a Corte de Contas, por meio da Resolução 9/2016, mudou seu entendimento e determinou a inclusão dos gastos em questão na despesa com pessoal a partir de 2017.

Em que pese a alteração promovida pelo TCE, a Assembleia Legislativa de Goiás promulgou, em 2017, as Emendas Constitucionais n으 54 e nำ55/2017, sendo que a primeira acresceu o § 8o ao artigo 113 a fim de não computar as despesas com pensionistas e IRRF, e a segunda alterou o caput do referido artigo com o escopo de definir a vigência inicial das exclusões (2o quadrimestre de 2017).

Tal entendimento era seguido por todos os Poderes e órgãos, com exceção do TCE, até o STF, em decisão liminar datada de 11/09/2019, suspender a eficácia das citadas emendas constitucionais, sob o fundamento de violação da competência da União ao flexibilizar normas gerais federais de responsabilidade fiscal, conforme ADI no 6129 .

Em resumo, conclui-se que, de 2001 a 2018, seja por decisão do TCE ou da Assembleia Legislativa de Goiás, a despesa com pessoal consolidada do estado não era composta pelos valores relativos ao IRRF e pensionistas. 
Esclarecidos os fundamentos das exclusões, passa-se à análise dos índices da despesa total com pessoal (DPT) oficialmente divulgados e das projeções realizadas pelo próprio estado, no que concerne aos exercícios de 2016, 2017 e 2018.

Em 2016, a DPT oficial foi de $49,26 \%$ da RCL, ao passo que, se considerados os gastos com pensionistas e IRRF, o percentual subiria para 54,48\%. Em 2017 foi de 47,79\%, sendo que o enquadramento correto representaria 56,71\%. Por fim, em 2018 foi de 53,69\%, enquanto que a projeção mostrou que deveria ter sido de 64,36\% da RCL. O Gráfico 2 a seguir ilustra essa trajetória.

Gráfico 2 | Comparativos dos percentuais da RCL aplicados na despesa com pessoal do Estado de Goiás (2016 - 2018)

$70,00 \%$

$65,00 \%$

$64,36 \%$

$60,00 \%$

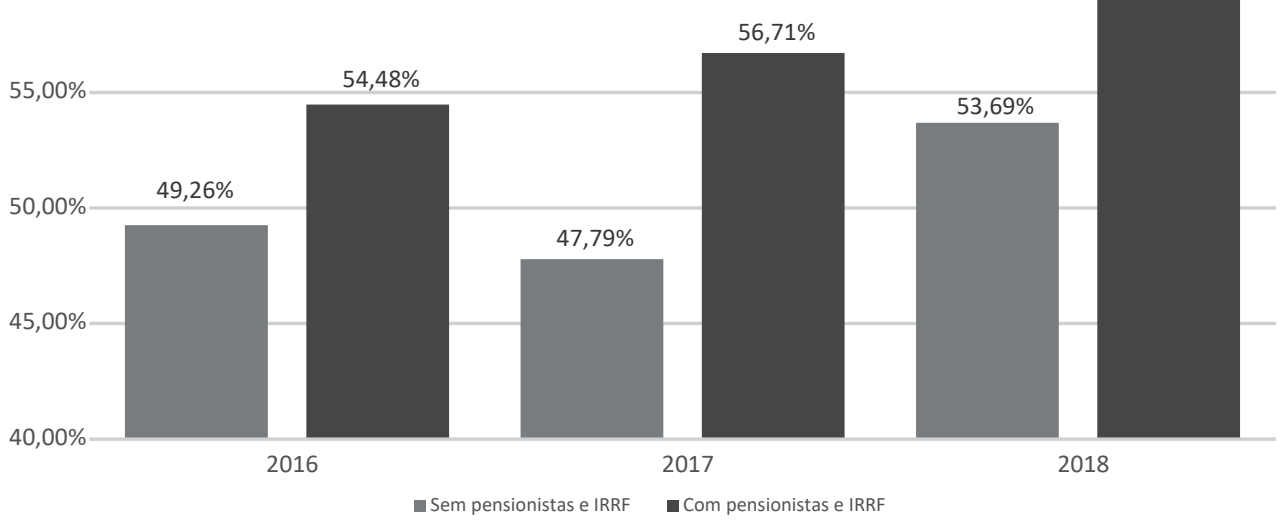

Fonte: elaboração própria.

Do exposto, demonstra-se que o estado, ao excluir as referidas despesas, teve um ganho fictício de margem de quase $7 \%$ dentro do limite global em 2018, abrindo brecha para o ente gastar com pessoal cerca de 1,3 bilhão de reais até atingir a proporção de $60 \%$ da $\mathrm{RCL}$, quando, na verdade, deveria adotar o caminho inverso, ou seja, acionar as medidas previstas na Constituição Federal e na LRF para a redução da despesa com pessoal. 
Ademais, ao incluir as rubricas de IRRF e pensionistas no cálculo da DPT, constata-se o valor de $\mathrm{R} \$ 928$ milhões além do limite de $60 \%$ da RCL, que equivale a quase $70 \%$ do déficit fiscal (R\$ 1,340 bilhões) e a aproximadamente 39\% do déficit previdenciário (2,411 bilhões) do Estado de Goiás em 2018.

Como já dito acima, Goiás decretou estado de calamidade financeira em 2019 e vem, reiteradamente, pagando seus servidores com atraso, conforme noticiado pela imprensa. 